\title{
0 Ideb e as políticas educacionais na região metropolitana de Curitiba
}

\author{
ANDRÉA BARBOSA GOUVEIA* \\ ÂNGELO RICARDO DE SOUZA* \\ TAÍS MOURA TAVARES ${ }^{* *}$
}

\section{RESUMO}

Este artigo apresenta os resultados de pesquisa sobre a efetividade das políticas educacionais na Região Metropolitana de Curitiba e Litoral do Paraná (RMCL), considerando o cotejamento entre os resultados dos municípios desta região no Índice de Desenvolvimento da Educação Básica - Ideb e outros indicadores sociais e econômicos (Índice de Desenvolvimento Humano, Taxa de Pobreza) e educacionais (Gasto-aluno, Taxa de Crescimento de Matrículas). As principais conclusões apontam para a existência de correlaçōes entre as variáveis sociais e

\footnotetext{
* Professora do Setor de Educação da Universidade Federal do Paraná (UFPR), pesquisadora do Núcleo de Pesquisa em Política, Gestão e Financiamento da Educação (NuPe) (andreabg@ufpr.br).

** Professor do Setor de Educação da Universidade Federal do Paraná (UFPR), pesquisador do Núcleo de Pesquisa em Política, Gestão e Financiamento da Educação (NuPe) (angelo@ufpr.br).

*** Professora do Setor de Educação da Universidade Federal do Paraná (UFPR), pesquisadora do Núcleo de Pesquisa em Política, Gestão e Financiamento da Educação (NuPe) (tavarestais@ufpr.br).
} 
econômicas (Taxa de Pobreza, IDHM) e o desempenho escolar medido pelo Ideb, mas são os recursos investidos em educaçáo, principalmente, que determinam sua qualidade na Regiáo Metropolitana de Curitiba e Litoral do Paraná.

Palavras-chave: educação básica, Ideb, políticas educacionais, rendimento escolar, qualidade do ensino.

\section{RESUMEN}

Este artículo presenta los resultados de una investigación sobre el grado de efectividad de las políticas educativas en la Región Metropolitana de Curitiba y el Litoral de Paraná (RMCL). Tales conclusiones se apoyan en la comparación de los resultados obtenidos por los diversos municipios de dicha región, que se ven reflejados en el Índice de Desarrollo de la Educación Básica (Ideb), con otros indicadores socio-económicos (como el Índice Medio de Desarrollo Humano (IMDH), y la tasa de pobreza) y educativos (gasto por alumno y tasa de crecimiento de la matrícula). Las principales conclusiones indican la existencia de correlaciones entre las variables sociales y económicas (Tasa de pobreza e IMDH) y el desempeño escolar medido por el Ideb. Sin embargo, son los recursos invertidos en educación, principalmente, los que determinan su calidad en la Región Metropolitana de Curitiba y el Litoral de Paraná.

Palabras clave: educación básica, Ideb, políticas educativas, rendimiento escolar, calidad de la enseñanza.

\section{ABSTRACT}

This article presents the results of a research about the effectiveness of educational politicies in Curitiba's Metropolitan Area and the coast of the State of Paraná (RMCL). The text compares the results of all counties in Ideb - Brazilian Basic Education Development Index with other social and economic indicators (Human Development Index - IDHM; Poverty Index) and educational indicators (Per capita student cost; Enrolment Index). The main conclusions point to the existence of a correlation between the social and economic variable (Poverty index and IDHM) and school performance as measured by Ideb. However, the financial resources invested in education are the most important factor to determine the educational quality in RMCL.

Keywords: elementary education, Ideb, educational policies, learning performance, teaching quality. 
O Índice de Desenvolvimento da Educação Básica (Ideb), lançado em 2007, pelo Ministério da Educação, é um indicador educacional que relaciona rendimento escolar (aprovação) e desempenho (proficiências) em exames padronizados. E se apresenta como um importante instrumento de verificação do cumprimento das metas fixadas no Termo de Adesão ao Compromisso Todos pela Educação, eixo do Plano de Desenvolvimento da Educação, que trata da educação básica.

Ao relacionar fluxo e aprendizagem, esse indicador permite aferir dois objetivos essenciais da política educacional em curso, com impacto em todo o sistema educacional (federal, estaduais e municipais): a contenção do abandono escolar e a garantia da aprendizagem efetiva. Consideramos, para efeitos deste estudo, o Ideb como uma medida que permite avaliar parte importante do dever do Estado com a educação, uma vez que este índice dá condiçóes de se compreender a extensão da ação pública no cumprimento ao dispositivo constitucional acerca da necessidade de se garantir qualidade educacional aos brasileiros e brasileiras (Brasil, 1988, art. 206, VII); portanto, o Ideb é um instrumento que pode dimensionar, mesmo que em parte, a efetividade das políticas educacionais.

Considerando que o Ideb é um recurso novo de avaliação e acompanhamento da educaçáo nacional e que não há estudos suficientes sobre ele, este estudo se propóe a uma exploração preliminar do índice, buscando compreender melhor as possíveis relaçóes entre o Ideb e outros indicadores sociais. Dadas as dimensões (e limitaçôes) da proposta deste artigo, optou-se prioritariamente pela exposição e análise dos dados da pesquisa, sendo que as necessárias discussóes teóricas mais aprofundadas sobre o uso de índices como medida na/da política educacional, devem ser inferidas com base naquelas análises.

A meta nacional norteia todo o cálculo das trajetórias intermediárias individuais do Ideb para o Brasil, unidades da Federação, municípios e escolas, a partir do compartilhamento do esforço necessário em cada esfera para que o País atinja a média almejada no período definido. As metas intermediárias do Ideb, com início em 2007, foram calculadas nos âmbitos nacional, estadual, municipal e para cada escola, a cada dois anos. A meta para o País é chegar à média 6,01 em 2021, e cada sistema evolui progressivamente partindo de pontos distintos, o que permite considerar as desigualdades regionais e locais existentes no País.

\footnotetext{
${ }^{1} \mathrm{O}$ Ideb é calculado em uma escala de 0 a 10 . A metodologia para cálculo do índice está disponível em: http://ideb.inep.gov.br/Files/Site/Download/Nota_Tecnica_Ideb.pdf.
} 
Essa desigualdade pode ser encontrada na Região Metropolitana de Curitiba e Litoral do Paraná (RMCL), constituída por 33 municípios cujas condições são bastante diversas, especialmente no que tange ao financiamento das políticas sociais (Gouveia; Souza, 2005).

Dentre aqueles municípios temos 26 que, exceto o litoral, compõem a Região Metropolitana de Curitiba, oficialmente declarada (Paraná, 2002). Estimativas do IBGE apontam que em 2006, esta região possuía 3.880.000 habitantes, concentrando o maior Produto Interno Bruto (PIB) da regiáo sul e o terceiro maior do país. O PIB per capita na regiáo era, em 2002, da ordem de $\mathrm{R} \$ 9.676,00$, porém com variaçóes muito grandes entre os municípios (de R \$ 2.925,00, em Itaperuçu a R \$ 44.477,00, em Araucária).

O Índice de Desenvolvimento Humano Médio (IDHM)² da região, em 2000, era de 0,824, evidenciando-se grandes desigualdades internas: de um lado, municípios com índices muito baixos, como os localizados no Vale do Ribeira, que possui os piores indicadores do Estado do Paraná, e, de outro, municípios com índices entre os mais elevados do Estado.

As diferentes condições sociais, na região, expressam-se também na desigualdade do Ideb das redes municipais de ensino de cada cidade. De modo geral, os resultados do Ideb crescem de forma proporcional ao IDH-M ${ }^{3}$ e de forma inversamente proporcional à taxa de pobreza dos municípios. Considerando como medida de correlação o Coeficiente de Pearson, obtém-se o índice de 0,72 no cruzamento dos resultados do Ideb com o IDH-M, e de -0,63 no cruzamento do Ideb com a taxa de pobreza. Tal tendência pode ser vislumbrada no gráfico 1 .

${ }^{2} \mathrm{O}$ IDH é calculado conforme metodologia que toma o PIB per capita, o poder de compra da moeda de cada país, a longevidade e expectativa de vida e os níveis educacionais da população. Trata-se de um índice que é referência internacional sobre o desenvolvimento humano (Disponível em: http://www.pnud.org.br/idh/, acesso em junho de 2008). Contudo, para mensurar o nível de desenvolvimento humano de municípios as dimensões são as mesmas - educação, longevidade e renda -, mas alguns dos indicadores usados são diferentes. Embora meçam os mesmos fenômenos, os indicadores levados em conta no IDH municipal (IDH-M) são mais adequados para avaliar as condiçóes de núcleos sociais menores (Disponível em: http://www. frigoletto.com.br/GeoEcon/idhmcalc.htm, acesso em julho de 2008).

${ }^{3}$ Neste artigo, utiliza-se IDHM para Índice de Desenvolvimento Humano Médio e IDH-M para Índice de Desenvolvimento Humano Municipal. 


\section{Gráfico 1 - Ideb, IDH-M e taxa de pobreza - municípios da RMCL (em índices)}

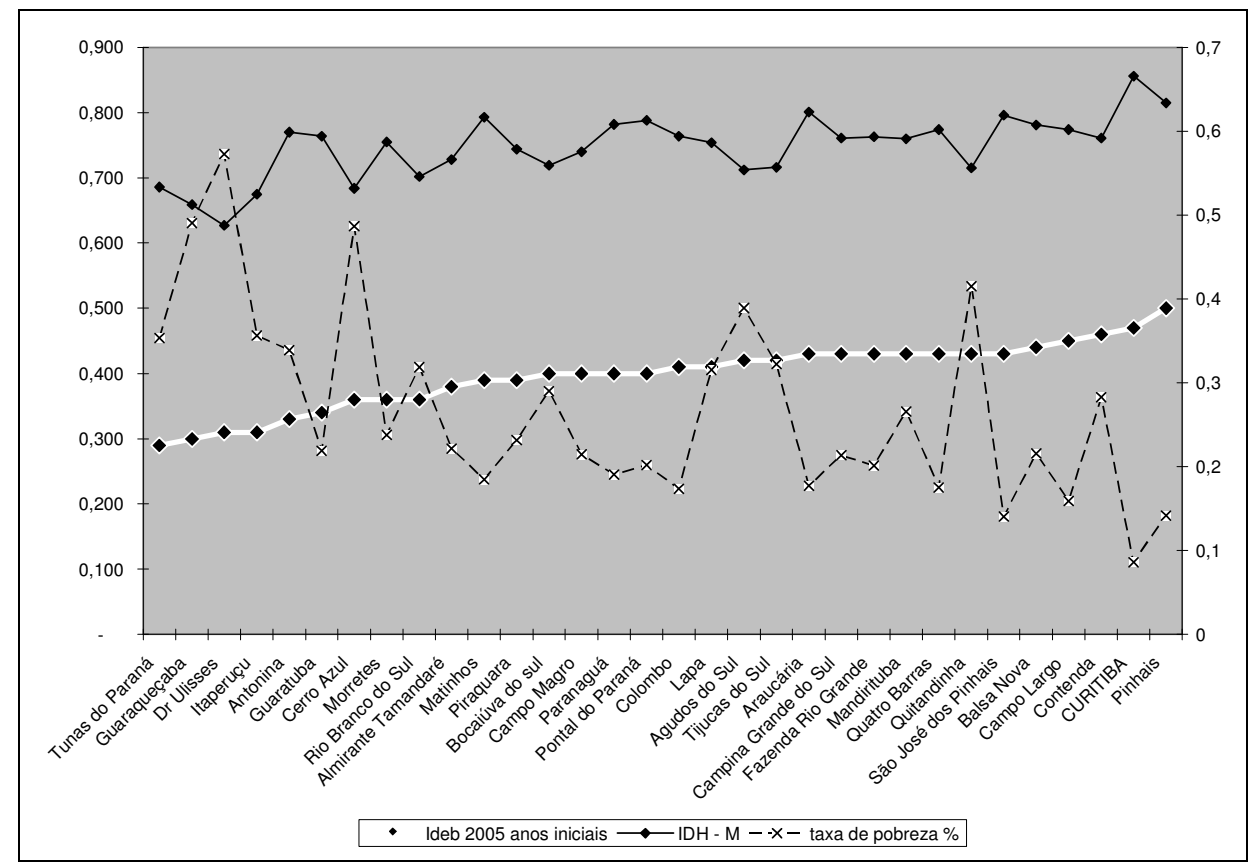

Fonte: IBGE; MEC-Inep; Banco de dados do NuPE/UFPR.

Obs.: Dados do Ideb de Adrianópolis não estavam disponíveis.

Números do Ideb divididos por 10.

Observe-se que o eixo à direita do gráfico correponde ao Ideb. Este varia, nos municípios considerados, entre 2,9 e 5,0 como pode ser visualizado seguindo a linha branca do gráfico; o eixo à esquerda do gráfico corresponde aos índices do IDH-M e à taxa de pobreza. Os municípios mais pobres, tendencialmente, apresentam menor Ideb, entretanto, como fica evidente na distribuição dos pontos no gráfico 1, essa tendência geral contém exceçôes. Ainda que os resultados escolares se devam, em parte, às condiçôes sociais dos municípios em que as escolas estão inseridas, há outros elementos que influenciam tais resultados.

A literatura tem demonstrado (Soares, 2004) que parte considerável dos resultados escolares podem ser explicados por características individuais dos alunos. Neste caso, pesam, além das condiçóes sociais, as de gênero e etnia dos estudantes. Embora tais condiçóes individuais agreguem alto poder explicativo, não esgotam o debate, posto que há elementos das condiçóes de oferta da escola que interferem no 
resultado. Tais condições são resultado das políticas educacionais em nível macro, ou seja, nas açóes do sistema de ensino, e são resultado da organização e gestão escolar, em nível micro. Neste artigo, são apresentados dois aspectos das políticas educacionais para explicar os resultados escolares das escolas municipais de ensino da RMCL: gasto aluno/ano e incremento da matrícula.

Para fazer isso, cabem algumas considerações sobre os pontos de exceção na relação geral apresentada no gráfico 1 . Nos gráficos seguintes, localizando apenas os dez municípios que estão com Ideb igual ou abaixo do nacional para as séries iniciais do ensino fundamental $(3,8)$, podemos perceber que um índice maior não decorre necessariamente de um IDH-M mais alto e de menor taxa de pobreza. Porém, é importante observar que, nesse grupo, os quatro municípios com o pior IDH-M também apresentam o pior Ideb, bem como dos quatro com menor taxa de probreza, três têm o maior Ideb.

\section{Gráfico 2 - Ideb e IDH-M - municípios da RMCL (menores índices)}



Fonte: IBGE; MEC-Inep; Banco de dados do NuPE/UFPR. Obs.: A escala à esquerda equivale ao Ideb e a da direita ao IDH-M.

A mesma relação pode ser observada entre os municípios que possuem Ideb superior ao nacional; ainda que neste bloco a Correlação de Pearson entre o Ideb e a taxa de pobreza continue alta $(-0,859)$, a correlação entre o Ideb e o IDH-M cai de forma significativa $(0,471)$. Encontram-se, neste bloco, municípios com taxa de pobreza superior a 30\% e com Ideb maior que a média nacional; chama a atençáo, também, o fato de que o município com o maior Ideb de todo o conjunto (Pinhais, com 5,0), não é o que apresenta a menor taxa de pobreza e nem o maior IDH-M. 
Os melhores índices, desses dois indicadores sociais, são da capital, que apresenta o segundo Ideb entre as redes de ensino consideradas. Pode-se problematizar tal situação menos pela inconsistência da correlação e mais pela heterogeneidade interna do município polo da região, o que só pode ser analisado em estudo do município, desdobrado em bairros ou sub-regióes.

Gráfico 3 - Ideb e índice de pobreza municípios da RMCL (menores índices)

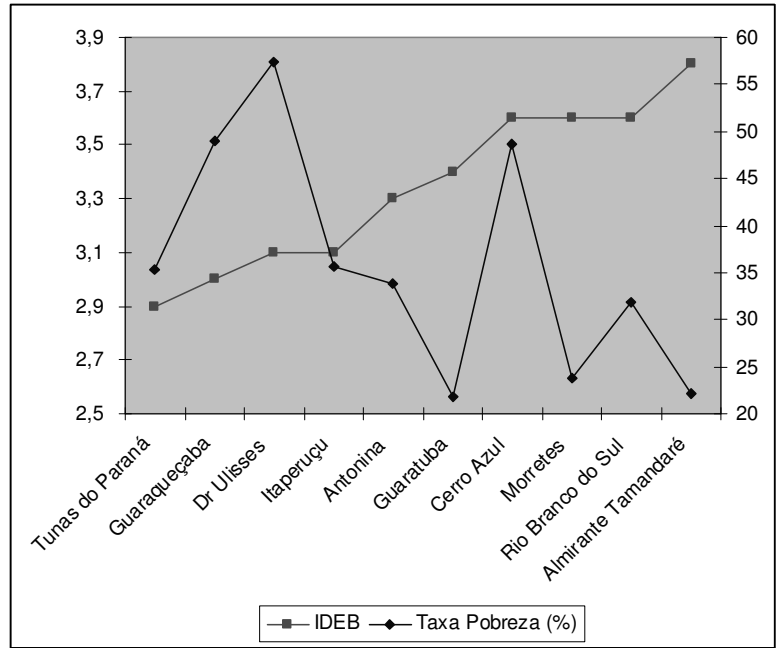

Fonte: IBGE; MEC-Inep; Banco de dados do NuPE/UFPR. Obs.:A escala à esquerda equivale ao Ideb e a da direita à taxa de pobreza.

Tais indicações parecem suficientes para que, considerando o contexto de desigualdade social, se passe aos efeitos das políticas educacionais nos resultados escolares. Assim, observamos dois elementos: o crescimento do gasto aluno/ano nas redes municipais em questáo e o crescimento da oferta de vagas. $\mathrm{O}$ primeiro elemento pode ser tomado como potencializador das condiçóes em que se realizam o ensino, e, o segundo, a existência da vaga, como condição inicial para haver política. É preciso ponderar que os recursos aplicados em educação não se transformam automaticamente em resultados; isso implica mediaçóes inúmeras em termos de condiçóes da oferta escolar. O que se pretende, neste momento, é apenas visualizar algumas tendências que possibilitem a provocaçáo do debate ${ }^{4}$.

\footnotetext{
${ }^{4}$ Esta pesquisa tem-se dedicado a construir indicadores mais precisos de condições de qualidade.
} 
Gráfico 4 - Ideb e IDH-M - municípios da RMCL (maiores índices)

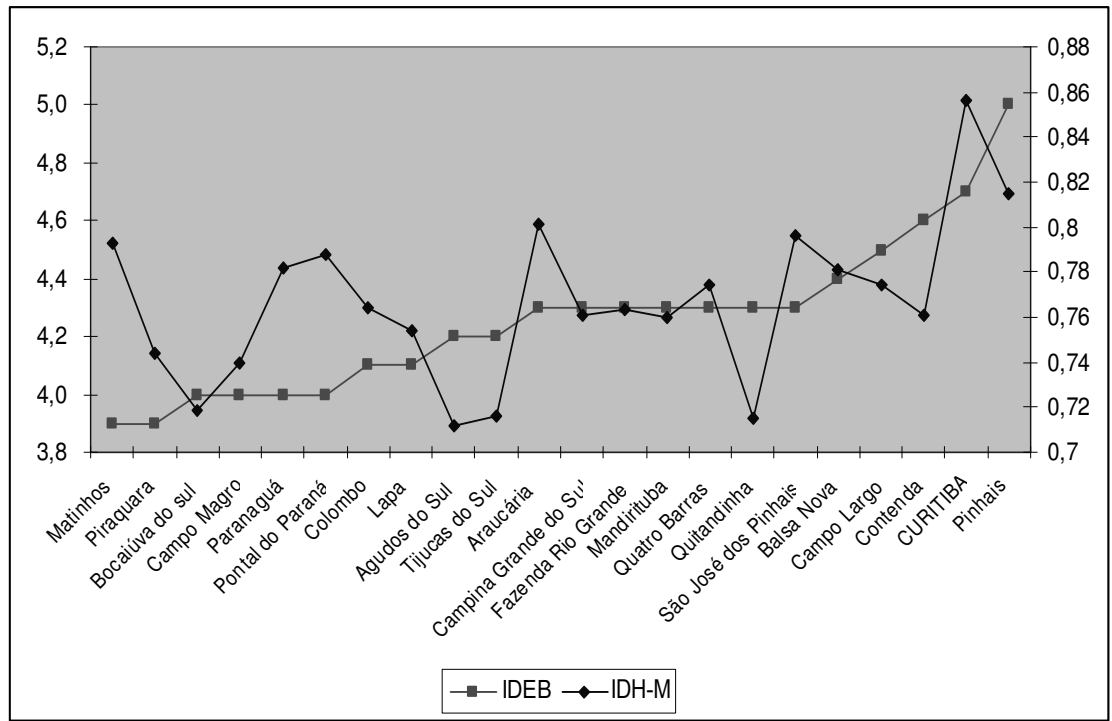

Fonte: IBGE; MEC-Inep; Banco de dados do NuPE/UFPR.

Obs.: A escala à esquerda equivale ao Ideb e a da direita ao IDH-M.

Gráfico 5 - Ideb e índice de pobreza municípios da RMCL (maiores índices)

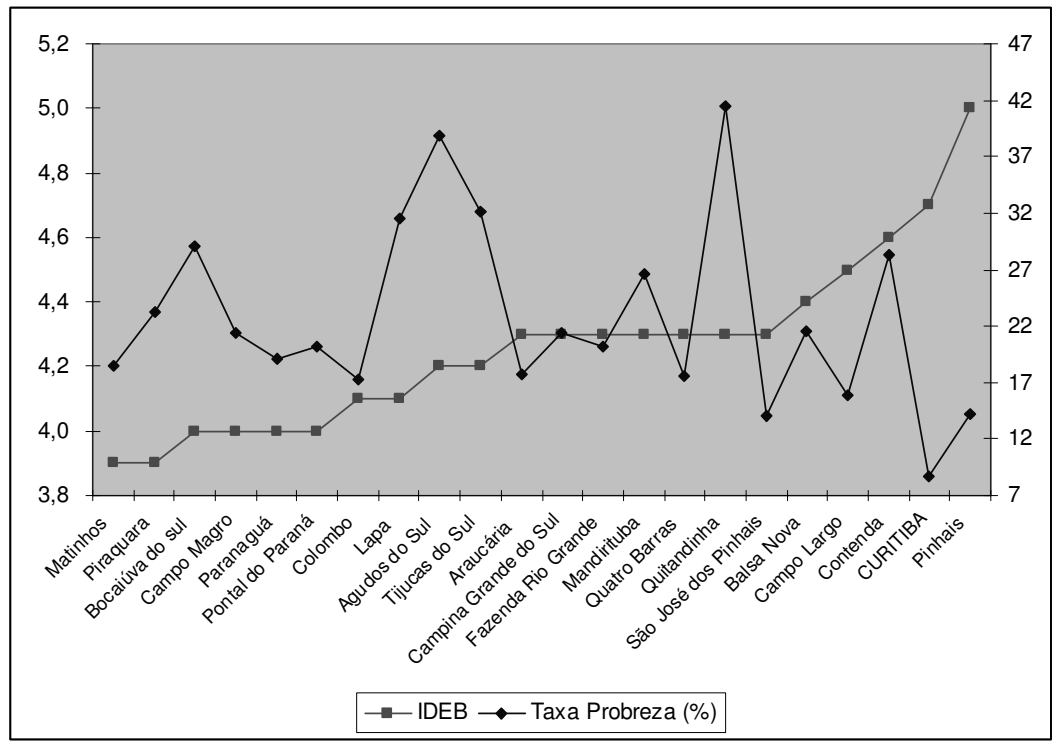

Fonte: IBGE; MEC-Inep; Banco de dados do NuPE/UFPR.

Obs.: A escala à esquerda equivale ao Ideb e a da direita à taxa de pobreza. 
O discurso corrente na política educacional é o da necessidade de incremento de recursos para a educaçáo, dado o baixo patamar de inversão em termos do PIB nessa área. Quando cruzamos, de forma direta, os resultados do Ideb nos municípios da RMCL e o valor do gasto aluno/ano em 2005, não é possível encontrar de imediato correlação estatística entre maior esforço municipal com gastos em educação e melhores resultados escolares, como poderíamos desejar. Como demonstram os dados da tabela 1, a correlação entre Ideb e as variáveis gasto aluno/ano e crescimento da matrícula, é muito baixa, ainda que, nos cruzamentos com o gasto-aluno, o índice de correlação seja um pouco maior. Entretanto, quando se agrupa os municípios por intervalos de Ideb, destacam-se algumas correlaçóes interessantes, principalmente naqueles com índice até 3,8, nos quais se observa que o incremento do gasto aluno/ ano entre 2001 e 2005 tem variação de 0,758 . É evidente que o uso de tal índice de medida de correlação permite apenas afirmar que as duas variáveis estão se movimentando na mesma direção, e não permite dimensionar quanto uma influencia a outra; mesmo assim, para o proposto neste artigo, parece suficiente para demonstrar que em um contexto muito precário os efeitos das políticas educacionais podem ter como parâmetro inicial o incremento de recursos.

Tabela 1 - Resultado da correlação entre variáveis Ideb, crescimento acumulado do gasto aluno/ano e crescimento da matrícula na RMCL

\begin{tabular}{l|c|c|c}
\hline $\begin{array}{c}\text { Faixas de resultado } \\
\text { do Ideb }\end{array}$ & $\begin{array}{c}\text { Ideb e crescimento } \\
\text { do gasto aluno/ano } \\
\mathbf{2 0 0 1 - 2 0 0 5}\end{array}$ & $\begin{array}{c}\text { Ideb e crescimento } \\
\text { da matrícula }\end{array}$ & $\begin{array}{c}\text { Ideb e gasto } \\
\text { aluno/ano } \\
\text { em 2005 }\end{array}$ \\
\hline Total & 0,304 & $-0,075$ & 0,380 \\
Até 3,8 & $\mathbf{0 , 7 5 8}$ & $-0,332$ & $-0,125$ \\
De 3,9 a 4,4 & $-0,100$ & $-0,090$ & 0,330 \\
Mais de 4,5 & $-0,383$ & 0,452 & 0,225 \\
\hline
\end{tabular}

Fonte: Banco de dados do NuPE/UFPR.

Obs.: Correlação de Pearson: varia de $-1 \mathrm{a}+1$.

Novamente, vale o exercício de visualizar tais movimentos em blocos de municípios. Entre os municípios com Ideb igual ou inferior ao índice nacional, há uma linha de crescimento do índice quase na proporção do aumento do investimento em educação. Tanto que os quatro municípios com menor investimento acumulam também os piores Ideb do grupo. É certo que há distorções, como é o caso de Guaratuba, que apresentou o maior crescimento no gasto-aluno e um Ideb mediano nesse conjunto de municípios. E, ainda mais, o município de Rio Branco do Sul que, com pequeno crescimento no gasto-aluno, obteve um dos maiores Ideb do grupo. 
Gráfico 6 - Ideb e gasto-aluno - 2001-2005 municípios da RMCL (menores índices)

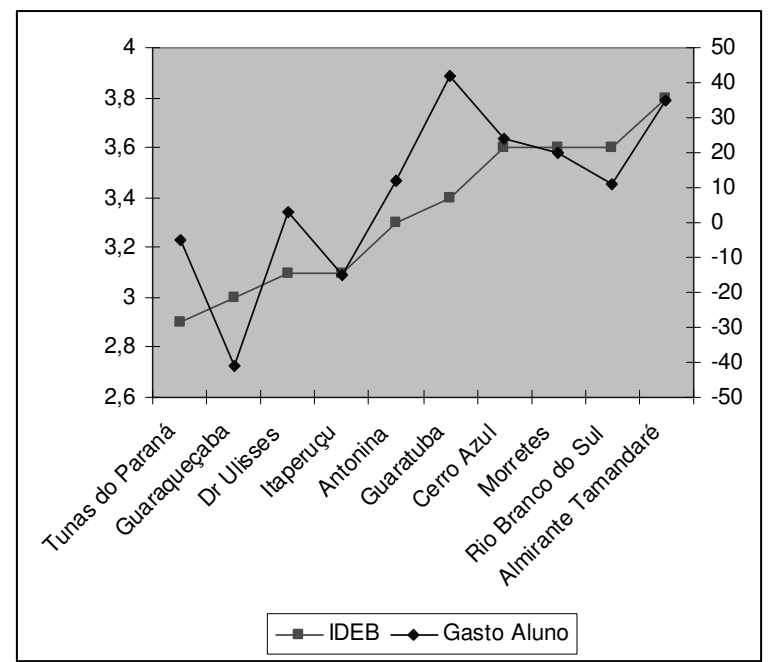

Fonte: IBGE; MEC-Inep; Banco de dados do NuPE/UFPR. Obs.: A escala à esquerda equivale ao Ideb e a da direita ao gasto-aluno.

Em relação aos municípios com Ideb superior ao nacional, aquela falta de dependência entre as variáveis retorna, pois parece não haver correlação entre o Ideb e o crescimento do gasto-aluno entre 2001 e 2005. Pontal do Paraná, por exemplo, apesar de ter apresentado o maior crescimento no gasto-aluno no período, possui um dos mais baixos Ideb, inferior a Quatro Barras, que teve queda no gasto-aluno. Se tomarmos o valor do gasto-aluno para 2005, veremos que Pontal do Paraná investiu mais por aluno $(\mathrm{R} \$ 2.524,00)$ do que Quatro Barras $(\mathrm{R} \$ 2.112,00)$.

A análise da relação entre o Ideb e o crescimento da matrícula também não apresenta indicativos seguros para a explicação do maior ou menor índice. O gráfico 8 mostra que o maior Ideb não corresponde necessariamente, nos municípios com Ideb igual ou inferior ao nacional, ao crescimento ou diminuição de matrícula nas séries iniciais do ensino fundamental público. Todavia, no outro extremo, temos o município de Tunas do Paraná, destacadamente um dos mais pobres de toda a regiáo, que apresentou o pior Ideb e a maior taxa de crescimento de matrícula nas séries iniciais entre 2001 e 2005, sugerindo que é possível haver, em algum nível extremo, relação entre o desempenho escolar e a distribuição de recursos e apoio, provocada pelo incremento de alunos (e escolas). Nos municípios com Ideb maior do que o nacional, parece que não há relação entre o índice e a taxa de crescimento de matrícula. 
Gráfico 7 - Ideb e gasto-aluno - 2001-2005 municípios da RMCL (maiores índices)

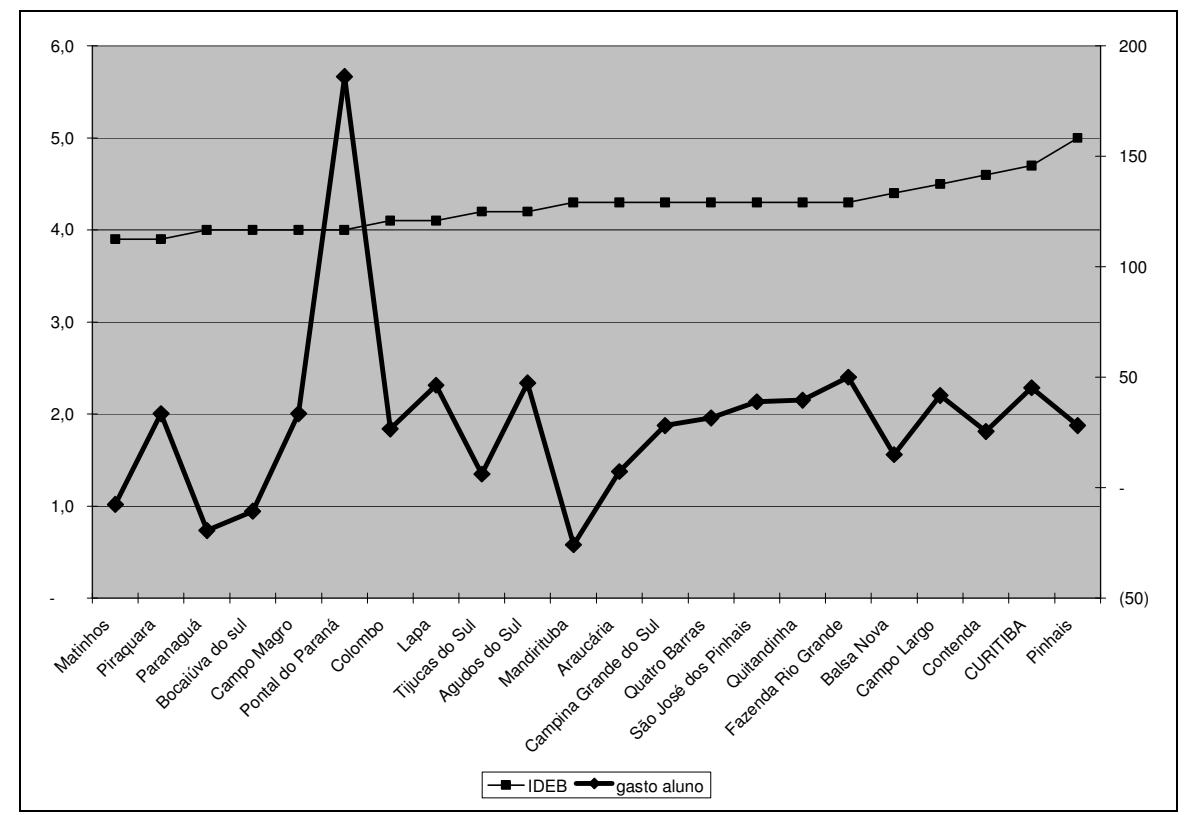

Fonte: IBGE; MEC-Inep; Banco de dados do NuPE/UFPR.

Obs.: A escala à esquerda equivale ao Ideb e a da direita à porcentagem de crescimento do gasto-aluno entre 2001 e 2005.

Gráfico 8 - Ideb e matrícula - 2001-2005 municípios da RMCL (menores índices)

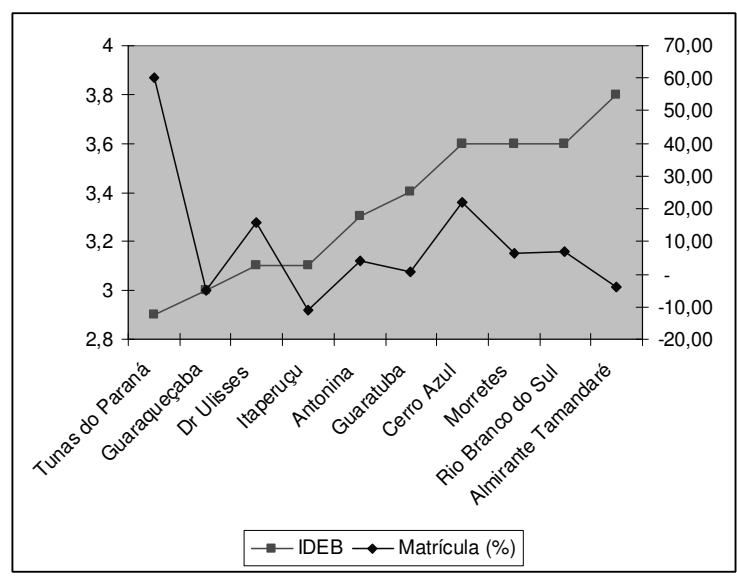

Fonte: MEC-Inep; Banco de dados do NuPE/UFPR.

Obs.: A escala à esquerda equivale ao Ideb e a da direita à taxa de crescimento de matrícula. 
Gráfico 9 - Ideb e matrícula - 2001-2005 municípios da RMCL (maiores índices)

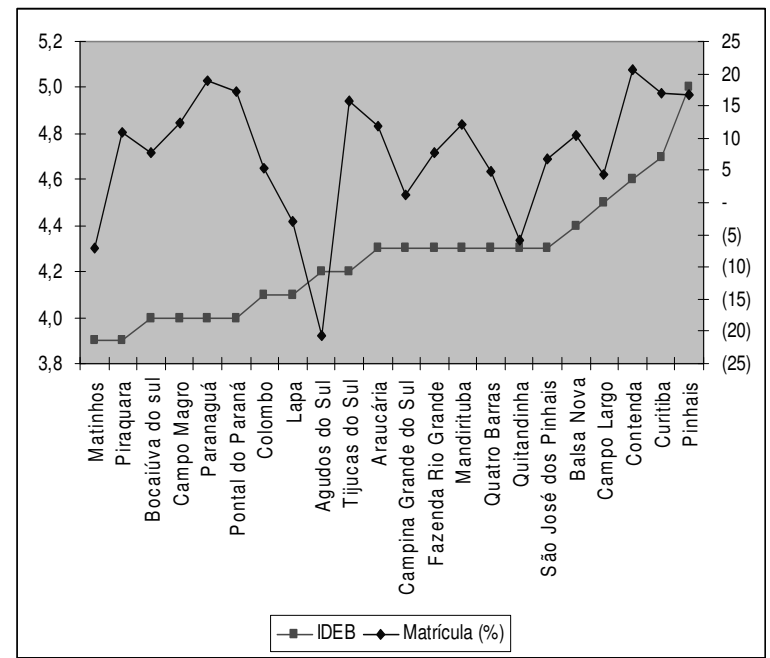

Fonte: MEC-Inep; Banco de dados do NuPE/UFPR.

Obs.: A escala à esquerda equivale ao Ideb e a da direita à taxa de crescimento de matrícula.

Os dados apresentados neste estudo demonstram que o Índice de Desenvolvimento da Educação Básica - Ideb, criado com o intuito de aferir o desempenho das escolas de educação básica no Brasil, tem relação forte com os indicadores de desigualdade social, o que pode indicar a reproduçáo de exclusóes sociais no âmbito educacional. Em outras palavras, o Ideb parece refletir não apenas as condiçóes de oferta educacional, mas o contexto de desigualdade social e econômica que caracteriza os usuários da escola pública na Região Metropolitana de Curitiba e Litoral, o que pode fazer deste índice instrumento interessante para problematizar as interfaces entre políticas públicas.

Ainda que exista correlação entre o IDH-M e a taxa de pobreza da população com o desempenho escolar, há um conjunto de aspectos que cumpre às políticas educacionais organizar e, dentre esses, o gasto-aluno mostra-se o mais importante, pois é o indicador que traduz a disponibilidade de recursos para o incremento da qualidade da educaçáo. Todavia, pelos dados apresentados, o impacto no crescimento do gasto-aluno é maior nos municípios mais pobres do que nos mais ricos. Naqueles, somada às extremas dificuldades gerais, a não priorização da educação com recursos públicos parece levar à derrocada qualquer tentativa de busca de melhoria na qualidade. Nestes, os demais fatores intra ou extraeducação parecem dar 
maior apoio para que, mesmo nos casos de menor investimento per capita, não se perceba tanto tal diminuição.

Finalmente, cumpre-nos dizer que estudos que busquem conhecer o Ideb em sua composição interna, discutindo os fatores educacionais que têm impacto sobre ele, são muito importantes e ainda escassos. Nosso intuito, com este artigo, foi o de apresentar os primeiros achados a respeito dos possíveis impactos provocados pelos elementos sociais e econômicos e sua relação com a efetividade da política educacional, tomando o Ideb como elemento que permite avaliar, ainda que parcialmente, tal dimensão.

\section{REFERÊNCIAS BIBLIOGRÁFICAS}

BRASIL. Constituição. Constituição da República Federativa do Brasil. Brasília, DF: Senado, 1988. BRASIL.Ministério daEducação.InstitutoNacional de Estudos e Pesquisas Educacionais Anísio Teixeira. Nota técnica: Índice de Desenvolvimento da Educação Básica - Ideb. Disponível em: <http://ideb.inep.gov.br/Files/Site/Download/ Nota_Tecnica_Ideb.pdf. $>$. Acesso em: maio 2008. Consulta ao Índice de Desenvolvimento da Educação Básica - Ideb. Disponível em: <http://ideb.inep.gov.br/Site/>. Acesso em: maio 2008.

GOUVEIA, A.; SOUZA, A. O Financiamento da educação em municípios da região metropolitana de Curitiba/PR/Brasil: os desafios frente à expansão da oferta numa região em crescimento. Scripta Nova: Revista Electrónica de Geografía y Ciencias Sociales, Barcelona, v. 9, n. 194, ago. 2005.

PARANÁ. Lei n. 13.512/2002. Dá nova redação ao parágrafo único do Art. $2^{\circ}$ da Lei n. 11.027, de 29 de dezembro de 1994. Disponível em: <http://www.comec.pr.gov.br/arquivos/ File/ leie13512-02.pdf.>. Acesso em: fev. 2009.

SOARES, J. F. Qualidade e equidade na educação básica brasileira: a evidência do Saeb. Archivos Analíticos de Políticas Educativas, v. 12, n. 38, p. 1-24, 2004.

Recebido em: novembro 2008

Aprovado para publicação em: janeiro 2009 
